\title{
Creating Values for Sustainability: Stakeholders Engagement, Incentive Alignment, and Value Currency
}

\author{
Frank T. Lorne and Petra Dilling \\ New York Institute of Technology-Vancouver, 1700-701 W. Georgia Street, Vancouver BC, Canada V7Y 1C6 \\ Correspondence should be addressed to Frank T. Lorne, florne@nyit.edu
}

Received 6 August 2011; Revised 18 October 2011; Accepted 20 October 2011

Academic Editor: Almas Heshmati

Copyright ( $) 2012$ F. T. Lorne and P. Dilling. This is an open access article distributed under the Creative Commons Attribution License, which permits unrestricted use, distribution, and reproduction in any medium, provided the original work is properly cited.

A shareholder theory of firm and a stakeholder theory of firm may differ in their respective evaluation method of firm performance. Both theories however recognize the importance of value creation as the economic role of firms as institutions. The New Institutional Economics (NIE) emphasizes incentives alignment, while also viewing stakeholder engagements as methods to expand the boundaries of firms. The difference in performance evaluation between the two approaches can be reduced if stakeholders, while formulating incentive alignment, also evaluate the mechanisms of establishing a common currency value. The concomitant development of stakeholder engagement, incentive alignment, and value currency creation is argued to be an evolutionary process with the efficiency implications of the two theories tending to converge.

\section{Introduction}

Economist Armen Alchian, in an influential piece in 1950 entitled "Uncertainty, evolution, and economic theory," articulated the basis for profit maximization as a criterion of survival for business firms. Over the years, the characteristics of firms have changed, perhaps responding to the same prophetic force of uncertainty and evolution predicted by Alchian, as the environment of business enterprises has changed significantly, responding to various stakeholders' needs. ${ }^{1}$ Are stockholders' interests being eroded? Stakeholders (including shareholders as a subgroup) reveal their interests via various types of engagement methods. Presumably, efficient engagement methods should generate values. If stakeholder considerations seek to encompass the intersection of business, environment, and society, the value so generated would satisfy the requirement of sustainable development according to a definition of the concept, and the value so created can be considered as value for sustainability. ${ }^{2}$ This paper examines to what extent sustainable values are capable of being captured. Stakeholders drive for a common value currency is argued to be also crucial.

The most basic common value currency to examine as a first-step endeavor to examine value currency is that provided by profit maximization, that is, the traditional financial performance of a firm. This task has been attempted by many in the academic profession. Although work in this direction had started early and has been ongoing, ${ }^{3}$ sustainability measures and accounting practices recognizing sustainability have yet to be integrated into the mainstream practices. Reasons for this can be numerous, ranging from the credibility of data used, problems concerning the measurement, and the estimation parameters, to lengths in time duration of a study, and so forth. Stripped to the basics, it boils down to a more fundamental question: would companies adopting sustainability indeed create values, and if so, for whom? ${ }^{4}$ Equity investors of companies can question why adopting sustainability initiatives for a company would necessarily increase the company's stock values and not merely an increase in costs. Therefore, the investment community can rightly question the source of values.

The current knowledge gap of accountants and financial analysts on the task of integrating sustainability value into an "economic" bottom-line measure suggests a communication as well as an information coordination problem between stockholders and various stakeholders. The dialogue here can resemble an exercise of practicing multiculturalism. One 
can imagine that it will be difficult, as a unifying paradigm between the shareholder concept of firm and the stakeholder concept of firm has yet to emerge. Again, the line of inquiry has to develop in steps. If conventional practices are framed by established "profit maximizing" mindsets, reforms in green accounting for matching social and private incentives may have to live with this constraint as a starting point. In this respect, although proposals of various alternative accounting techniques have been around, various techniques often are geared towards "what should be counted" rather than the incentive consequence of accounting specific items, with the stakeholders' ensuing effort in contributing to the creation of values not explicitly recognized. If so, a dialogue of creating a currency of value via the forging of finance and accounting methods can merely add to a state of cognitive dissonance, with stakeholders separately proclaiming what each subjectively considers as important.

We believe an emphasis on methods of evaluation, stakeholder engagement, incentive alignment of stakeholders, and their recognition of a value currency will sharpen the focus of a multiinterest dialogue. Since Coase [1], this approach has long been suggested as the foundation to understanding how people organize economic activities. Articulated as transaction-cost-reducing mechanisms, the theory of the firm and institutional economics, collectively known as the New Institutional Economics (NIE) problems, examine various ways that organizations and contractual arrangements can create value. ${ }^{5}$ The application of such concepts in examining the reasons behind the adoption of sustainable development and Corporate Social Responsibility (CSR) for firms has seldom been attempted. The exercise is not straightforward. The incentive alignment problem is more difficult to manage than that in the realm of the conventional theory of firm, as multicriteria evaluation for this broader problem is likely to be complex, encompassing but not limited to the single dimension of profit alignment common in the conventional principal-agent problem.

The strategy we use in tackling this problem starts out by focusing on whether values have been implicitly captured by financial performance. But instead of reviewing the empirical studies of the past and comparing the results with our own efforts, which consisted of mixed results, we want to concentrate on examining the theoretical reasons why sustainable values may be capturable (at least by the single dimension of profit criterion). If the reasoning is sufficiently compelling, empirical pattern becomes only a question of choosing the period of study being long enough to capture all the effects. Ultimately, all values created must be capturable if there are sufficient theoretical reasons for them to self-generate. This is the prophetic evolutionary approach articulated by Alchian; that is, the criteria people are choosing to evaluate themselves, subjective preferences included, may have to evolve from an evolutionary process, given the inherit nature of uncertainties.

The organization of the paper will be as follows. Section 2 brings out the insights of the NIE perspective for interpreting the Corporate Social Responsibility (CSR) stakeholders movement of firms. Section 3 provides some examples on how CSR and stakeholder engagements are taking place in the real world. Section 4 describes industry and academic efforts in forging values in terms of the profit maximization dimension. Section 5 accepts a broader value perspective that requires multidimensional criteria. The role of creating a common value currency by stakeholders must go together with stakeholder engagements for proper alignment of incentives.

\section{The New Institutional Economics (NIE) Perspective}

The term "new" does not mean "recent." Indeed, for over 70 years now since Ronald Coase published The Theory of the Firm (1937), NIE has grown to a rich body of theories addressing not only the original question of why firms exist, but also why different kinds of firms exist, Alchian and Demsetz [2]. This line of inquiry has been pursued in a large variety of studies as cited in endnote 5 . There can be a great deal of more applications of this in the stakeholder concept of firm, perhaps drawing attentions to issues on methods of stakeholder engagement, quality of information gathered in CSR, incentive alignment, nature of value creation, and so forth. We see at least four insights that the institutional approach of NIE can provide.

First, stockholders are not passive residue claimants. They are capable of generating efficiency implications in that, by entrusting ownership of a firm to the right individuals, who might also be the stakeholders (e.g., the employee), the ownership can induce efforts put in by those individuals for the purpose of increasing the value of the company. This proposition is well known in principal-agent literature, particularly addressing issues on executive compensation, labormanaged organizations, high-tech employee stock options, and so forth. However, the ramification of appropriate contractual forms for stakeholders contributing to sustainability concerns has not been sufficiently explored. Literature on the firm as a collection of stakeholders often emphasizes the universality and the broad scope of a firm's preference as a matter of moral responsibility rather than as a matter of incentives. The Global Reporting Initiative (GRI), for example, presumes a standard that would (or should) work for all firms in different industries in different countries. No logical reasons from the NIE perspective could support that type of rationale, as incentives to induce contributing efforts from stakeholders are ignored.

Second, the very notion of sustainability suggests that there is a time dimension in the nature of the problem. In particular, a firm in terms of its identity and its scope of stockholders and stakeholders composition may be changing over time. Can incentive alignment be maintained at all time? Indeed, it is possible that the firm as an "entity" can grow with changing characteristics, expanding and reducing the boundaries of firms (i.e., the scope of stakeholders), depending on the industry environment in which the firm is operating. If so, there can be a real question as to whether stock ownership can be aligned to match this changing nature of the firm with the passage of time and, more importantly, whether corporate financial planning is 
geared towards accommodating the changes. As this will be demonstrated via examples of current practices later in this paper, stakeholder development can be interpreted as a transitional process for extending firms' boundaries, rather than an overhaul of their objective function of profit maximization. Thus, Alchian's 1950 [3] proposition is not dead and indeed useful for providing a road map for this transitional process.

Third, incentives cannot be created out of thin air. There is a real question as to how values created should be registered on the balance sheet of a company. From the perspective of the entity approach in accounting, external costs and thus liabilities should be ignored except if it comes to the point requiring regulation in terms of a tax or some sort of a fine, and only then will it enter the financial statement, either as a cost or as a liability. This is clearly an unsatisfactory way of handling the problem, because it will provide every incentive for the company to avoid it. The alternative of how the problem should be addressed may require a more fundamental inquiry of the nature and the meaning of the term sustainability. Clearly, sustainability does not require external spillovers to be addressed at all costs. In recent years, most mission statements of sustainability had recognized the need for a comprehensive (compromising) treatment of environment, society, and economics. In other words, achieving a win-win outcome is the crux of sustainability. ${ }^{6}$ The fruits of any win-win efforts should result in values, and perhaps assets (tangible or intangible) capable of capturing it. Accounting practices may have to deal with how such assets should be measured.

Fourth, accommodating various idiosyncrasies is often at the heart of a sustainability mission-whether it is in the name of biodiversity, cultural identity, heritage, or preservation of the past. These idiosyncrasies could very well be the idiosyncrasies of the representatives of stakeholders. Indeed, what constitutes the values of the stakeholders (separately or together as a unit) and whether they can be captured in terms of some type of asset values can often be an open question. The NIE perspective treats various idiosyncrasies and the capturability problem seriously. Undoubtedly, there will be cases where the subjective values of the stakeholders cannot find a channel through the asset values of a company. There will also be cases where stakeholders have specific preferences regarding the type of assets owned by the company. If the stakeholders also happen to be the shareholders, there is no malincentive even if the stock values are lowered, as the real benefits to the stockholders in that case are the stock value plus whatever psychic values the stockholders can attain by owning the assets of their preference. This is not always the scenario, however. There can be cases where stakeholders, through their influence of the management board, select asset types for the firm that do not increase the value of the companies but the idiosyncrasies of the representatives. Therefore, we should not expect to see all companies practicing CSR uniformly increasing their corporate stock values, which are based on the sole criterion of profit maximization. The relevant question, then, is not whether CSR will increase corporate values. Rather, the right question to ask is in what situations and for what type of firms can CSR increase corporate values?

\section{Current CSR and Stakeholder Engagement Practices}

Although CSR cannot be said to have uniformly increased corporate stock values, the fact that it is widely practiced suggests that some values must exist. In our working paper review of 116 global public corporations publishing sustainability reports with GRI G3 guidelines, we found that companies providing extensive and useful CSR information are not necessarily limited to big players. Often, sustainability reporting was used as a strategic mission statement, usually in industries with relatively high-profit margins, having new equity and debt issues, and a well-functioning governance system. Indeed, Schaltegger and Burritt [4] pointed out that sustainability accounting can be used as decision support for business leaders. To the extent that good business decisions will eventually lead to good corporate values, the capturability of values is only a matter of time. Additionally, Burritt and Shaltegger [5] proposed an alternative way of viewing CSR in terms of its footprints on the managerial path: an information gathering process for purposeful decision making.

It is not sufficient to view CSR reports merely as an information gathering device, however. Information is gathered for a purpose, primarily for stakeholder engagement and ideas involvement. From the NIE perspective, it is also important to evaluate the contributing efforts of the stakeholders, as these efforts could in principle further increase the size of the pie. However, in our ongoing investigation of the stakeholder participation process of CSR, the transaction costs (including information costs) are often noted to be nontrivial. Problems of effective communication and the choice of appropriate communication channels, establishing a common vision, choice of performance indicators and metrics, administrative bureaucracies, and interest group politics, all of which contribute to the transaction costs of incentive alignment in a stakeholder engagement exercise. While management literature can help suggest methods of reducing these transaction costs, we expect an evolutionary process hypothesized in Alchian's 1950 article [3] eventually to sort out the best method for given circumstances. As an implication of the evolutionary approach, even if CSR reports generally do not explicitly mention the phrase "incentive alignment," it cannot be viewed as evidence disproving the significance of the research direction suggested in this paper. All companies adopting sustainability measures are going through some type of a trial-and-error process. Like farmers plowing soil not necessarily understanding economics, managers and CEOs do not need economic jargon to justify what they pragmatically implement for their companies.

In spite of noted difficulties of stakeholder engagement, there are success stories. These are usually reported at conferences involving industry participants, who gather for the purpose of sharing success stories. ${ }^{7}$ Our observation is that 
incentive alignment was evident in many companies' development programs. A dynamic evolution of firm boundaries as discussed in the previous section can also be found to be an implicit driving force for stories reported.

Several examples can be revealing.

\subsection{Intel's Efforts on Institutionalizing Stakeholder Engage-} ment. It is not surprising that large organizations such as Intel have Corporate Social Responsibility programs. Of interest is how they institutionalize some of their stakeholder relationships. General information in the dimension of community involvement of Intel, for example, can be found at http://www.intel.com/community. While specific examples in various countries have been noted on this website, the reported community solutions program in six countries in Africa seemed particularly promising in its potential for establishing win-win outcomes. Working with NGOs in these countries, this program worked under Intel's Corporate Strategic Alliances organization-a Corporate Social Responsibility branch of the company that "blends Intel's business purpose and social commitment throughout communities worldwide." Through direct or indirect assistance in education, healthcare, economic development, and environmental stewardship, Intel can leverage its technological capabilities in assisting NGOs in practical software applications for financial management methods, data storage, and communications. In turn this helps the NGOs' operations to be more transparent and thus reduce transaction costs between investors and investees of specific initiatives, and possibly within the NGOs themselves. In separate but related programs within Intel, the matching of business and customer value was also emphasized, evolving more and more from a "one size fits all" traditional method of development to a more customer-centric type of development process. The development acronym of DOME, which stands for design, office, manufacturing, and enterprise, is being discussed at a broad corporate level, addressing the question how these intangibles can be measured, monitored, and evaluated. By engaging in the design and the building of the "Green Building" Project in Israel, for example, Intel took an equity interest in the green movement in that community, attracting the participation of other "green suppliers," thereby further expanding on a win-win formula.

What does this example of Intel stand for in the context of the theoretical point we make in this paper? First, it is evident that the process is evolutionary, with strategic alliances being the vehicle to expand on the boundaries of the company. Second, the use of NGOs in stakeholder engagement is an intelligent way to minimize transaction costs, as stakeholder membership of particular types can be diverse and plagued with communication problems. ${ }^{8}$ Third, the engagement dimensions that Intel has chosen are found to be all "more or less" IT related. This suggested strong possibilities in the future on the capturability of return on Intel's investments. Agreeing on a multidimensional performance criteria was not an issue. The value currency issue in formulating an efficient stakeholder engagement does not seem to be a problem, as the single dimension of profit maximization is likely to capture all returns for Intel in the long run.
3.2. Adidas' Flexible Firm's Boundaries. In various community involvements of large corporations, the initial stage of developing win-win formulas can often be an unknown and thus difficult to be evaluated. Clearly, engaging specific interest groups in some permanent fashion at the beginning would be undesirable, as various moral hazard problems are to be expected. The example of Adidas being involved with beach cleanups (an environmental and social initiative) is revealing.

A young person who has a passion for preserving beach environments started out at a grassroots level of volunteering for beach cleanups in his community. The cleanup exercise eventually extended into other areas where the young man helped Adidas in developing labor practices for their outsourced companies. A small cleanup initiative thus went through a metamorphosis to become a crusade for outsourced companies to do "good" to the society and the environment-again illustrating an evolutionary process for the boundary of the firm to expand. The testimony was given by the young man, who, at the time of speaking at the conference, has become an "employee" of Adidas. Thus, an activity that was initially outside the boundary of a firm has transformed to an activity inside the firm. From the NIE perspective, this transition is illuminating.

Flexibility in firms' boundary is tied with a time development path. Kourula [6], following work by Halme and Laurila [7], characterized the degree of corporation stakeholder engagement into three levels, progressing initially from a distant and sometimes token gesture of sponsorship, to a more engaging format of dialogue, elevating to a form of strategic partnership that can be more permanent. Initial stakeholder engagement is likely to be event specific. Companies, by donating funding, grants, expertise, products, and services for a one-shot event, often may not generate sustainable values except for brand-name advertising.

The NIE perspective suggests that the transition process of stakeholder engagement will take various contractual forms, depending on the nature of information and the transaction costs involved. It is useful to further probe into why NGO as an organization structure that belongs to neither the state nor the private sector can play a unique role in this transition. Companies doing CSR often find fruitful interactions by leveraging the marketing niches of NGOs in dialogues through consulting, training, specific research, roundtables, certification systems, or auditing. Thus, the incentive alignment exercise is never like solving a principalagent problem in the conventional modeling literature of the theory of firm. Comparative static results are probably difficult to derive if a comparative study on the choice of contract is the academic focus.

Flexibility of boundaries goes with flexibility in the various stages of stakeholder engagement. It is unlikely that incentive alignments can be forged by design via stock allocation as a mathematical modeling problem. At best, what companies adopting CSR on the incentive front may want to do at the initial stage of an engagement exercise is to think of various gimmicks, for example, design competitions, scholarships, games, and so forth, so as to make engagement more incentive compatible and perhaps a way to bring out 
asymmetric information that is hidden. Examples of these are quite abundant in our casual observation.

\subsection{How Nokia Can Have the Cake and Eat It Too? CSR} is often preached as business ethics. The English words "social responsibility" suggest elements of devotion, donation, sacrifice, and unconditional volunteer work that is a matter of civic responsibility. Actions driven by moral responsibility incur unavoidable costs, with returns not to be expected, or at best as a secondary concern only. An NIE perspective will question that, as even for moral persuasion, there can be a choice as to what is more effective or less effective. Morality should not be merely a self-expression. Once we accept that the preference and action of recipients from an act of charity is important, the NIE approach of addressing transaction costs and incentive alignment questions immediately becomes relevant.

Consider the transaction costs involved with engaging stakeholders at a completely decentralized level, for example, of offering microcredit in undeveloped countries for mobile phones and services. Dr. Muhammand Yunus won a Nobel Peace Prize for that. Why was it a peace prize and not an economic prize?-even though microcredit was practiced successfully in various rural areas of less developed countries. Clearly, it was a contribution to economic development.

Perhaps it was because these activities were practiced as decentralized small-scale endeavors, initially driven by the moral persuasion of "doing good," and conducted only at village hair salons, restaurants, cafés, and retail shops, that is, stations for the less privileged group. It is not something initially dreamt to be run by large multinationals such as Nokia.

The evolutionary approach suggested by Alchian would argue that the starting point of a movement is irrelevant. What started out as an act of charity could evolve into ventures of great economic significance. Again, the transitional stage of middlemen could be crucial. Nonprofit organizations such as the Grameen Foundation USA can start out as an organization purely for the purpose of promoting the microfinance idea, but it can evolve into institutionalizing relationships, producing win-win results for both the corporation practicing CSR and the benefiting communities. The middleman position in this case is not a task that can be accomplished by anybody. Indeed, GFUSA has shown their comparative advantage in that respect by setting up the Grameen Technology Center as early as 2001. Aside from creating jobs, improving access to health care, education, and other services connecting isolated communities and stimulating local economies, the center implemented the concept of microfinance with technology to create innovative and sustainable solutions for microfinance institutions (MFIs). The village phone system initiated in Bangladesh was thus being leveraged by Nokia in implementing similar systems in Uganda and Rwanda. An NIE view of the problem would expect a strategic partnership or something resembling that of GFUSA and Nokia to develop in other industries as well.

\section{Forging Valuation as a Profit Maximization Problem}

The three cases discussed in the last section revealed ingenious organization development for capturing return to values arising from sustainable development initiatives, whether the source of value created was a reduction in transaction costs, an expansion of market size (shifts in demand), or a better chain value management (shifts in supply). Is that good enough to show that 21 st century corporations are moving toward improvement, rather than regressing to political quagmires? Many academicians and policy makers, while not considering that the current CSR development will lead to quagmires, also do not feel stakeholder engagement to be sufficient. Wall Street has yet to buy into the contribution of CSR. But until the accounting and the finance profession can figure out a method of counting CSR contribution, all methods of valuation are only implicit. It may or may not be reflected in terms of stock prices, of which the values are derived from profit maximization.

Aside from academic efforts of gauging implicit valuation reported in endnote 3 in the introduction of this paper, practitioners are now taking steps to explore practical ways of valuation, so that values generated from CSR can be shown in balance sheets or income statements, directly affecting valuations. Before we describe the development in this direction, let us first evaluate whether there are theoretical reasons for CSR to be counted as an item of profit maximization.

Our literature search suggested that, aside from one past work done by one of the authors of this paper, there are several research groups who have also probed into this question seriously. ${ }^{9}$ Their approach can be summarized as follows.

Starting with a conventional approach of present value calculation of how shareholders value is to be determined, the approach specifically addresses the question of "value drivers." Using the Shareholder value network approach in Rappaport 1986, the Sustainable Value approach proposed reclassifying value drivers into three groups.

(1) Working capital investments and fixed capital investments. These are cash outflow items that may have more immediate negative impact on shareholders, although they were incurred because, in the long run, there will be payoffs, with future positive cash inflow items to offset.

(2) Sales growth, operating profit margin, income tax rate, and value growth duration-these are conventional value-generating drivers that are expected to result in cash inflows. Note further that cost accounting from sustainability adoption can have a positive as well as a negative impact.

(3) The cost of capital influences shareholder values through appropriate discounting for cash-in- and cash-outflow items. If one envisions the CSR reporting as a risk management exercise, companies engaging in these activities are likely to have better control of risks and thus have a lower cost of capital. This is a very interesting area of research and probably one of the most forceful arguments that contribute to shareholder values. 
Practitioners can examine through examples how the capturing of values can come about with the categorization above. The approach suggested potential economic rationales for higher markup prices for high-quality green products - as higher prices lead to higher operating profit margin. Likewise, by addressing the cost components of operations, companies that have high energy and material costs can reduce expenses by adopting new technologies and through fuel substitution. The interplay of fixed and variable costs can be instructive in this respect in that not all alleged sustainable measures are cost effective. For example, environmental protection measures that are capital intensive, such as end-of-pipe filters, could reduce shareholder value. Changing strategies from being capital intensive to being capital extensive, that is, via building of economies of scope, can be quite insightful. ${ }^{10}$

What about recent efforts by practitioners? There are notable efforts from the UNEP FI and the WBCSD group. UNEP FI is the United Nations Environment Programme, Finance Initiative. WBCSD is the World Business Council for Sustainable Development. The two organizations jointly organized two-day pilot workshops in various cities of the world, bringing together selected investor companies and investee companies with an aim "to develop a common view on sustainability value, to understand the current gaps in communicating Environment, Social and Governance (ESG) information, and to improve the integration of ESG performance into company valuation." ${ }^{11}$ For example, in a July 2008 meeting of such workshop between investor and investee companies, a McKinsey Quarterly report was discussed, showing that "most companies..have at least 30 alliances, and many have more than 100." Yet, in a sample of over 500 companies worldwide, it was found that fewer than one in four have adequate performance metrics, failures to recognize "deal structures, types of partners, or functional tasks" were widely observed, and, indeed, senior managers do not know if the alliance portfolio can support corporate strategies. Baruch Lev of New York University proposed that efforts should be spent on concrete information disclosure as a possible next-step solution to the forging of accounting and finance practices - that is, "set up standardized disclosure templates for industry groups, (essentially codifying successful voluntary practices)". ${ }^{12}$ However, as of 2008 , development in this direction seemed suggestive and open ended.

\section{Quest for a Value Currency}

Although there are theoretical reasons to believe that CSR initiatives can find their value in the traditional valuation paradigm as discussed in the last section, it is a big jump to the assertion that all values arising from CSR initiatives are capturable in the conventional (profit maximization) valuation paradigm. Practitioners' efforts in this direction also seem to be at the level of merely suggestive at this stage of development. The fact that, at the time of this writing, stock analysts in the world generally do not treat CSR report with the same level of rigor and importance as corporate earnings report (monitor quarterly) would suggest that CSR valuation as profit maximization has yet to be included in the mainstream.

If all stakeholder engagements resemble the few examples discussed in Section 3, where values so generated can be channeled back into the income stream of the companies doing the CSR, values for sustainability are arguably capturable in stock values in the long run, even though they may not reveal their significance in the short run. This may be an overly optimistic projection, however, as not all stakeholder engagements can have the same strategic success that we have highlighted.

One perhaps may think that taking a generalist's view on valuation will be more pragmatic than the NIE view. Some in the management field in business have already suggested alternative methods to value CSR other than the single-dimensional measure of profit maximization judged solely in terms of stock prices. Aside from the use of the popular Triple Bottom Line (TBL) method widely used in CSR reports, there were proposals to design metrics such as Balanced Score Board and Value-Based Management as well as doing meta-analysis of various kinds to evaluate companies' performance. ${ }^{13}$ In our opinion, the case for developing multidimensional metrics can be pushed too far. Indeed, Brown, Dillard, and Marshall of Portland State University, in a series of methodological papers on accounting since 2005, suggested a radical departure from the way we should be viewing corporations, expressing doubts on whether a monetary unitized method of accounting is an ideal goal to pursue. $^{14}$

We propose a more modest way to deal with the multidimensional value measurement problem that will be consistent with the NIE perspective: the quest for a value currency, with stock value being a limiting case where multidimensional measures can be collapsed into a single measure of profit maximization. The use of an NIE approach for addressing to stakeholder engagements, as we have done in an earlier section, suggested that incentive alignment be treated as a principal-agent problem as in the NIE literature. However, this is only so if values are fully capturable in a single dimension of profit. Given that values can be multidimensional, our proposition must be modified to include cooperative efforts of stakeholders in determining a currency value. This needs to be undertaken in conjunction with incentive alignment during a stakeholder engagement process in order to bring about the efficiency result as in the traditional theory of firm. Theoretically, including an extra dimension of cooperative participation is not a conceptual departure from a typical principal-agent problem.

A hypothetical example may illustrate the nature of this interaction. Suppose that the environmental stakeholders insist that a reduction of $\mathrm{CO}_{2}$ is an absolute measure of value, one which can only be evaluated independently in the environmental dimension of a TBL. Suppose that the environmental stakeholders can convince the other stakeholders (e.g., the employees) that a reduction in $\mathrm{CO}_{2}$ is "valuable" and thus should be counted as part of the compensation to the employees. The hedonic component of this compensation package, under market competition, would self-select employees willing to forego monetary compensation for a 
psychic benefit. The reduction in the wage component, other things held constant, means an increase in profit.

A little extension in thinking would suggest that the above example does not need to concentrate on an exclusive group of stakeholders only. The perceived benefit could be spread out, including the shareholders. To a wide extent, these cooperative quests for values have been carried out already; the stock of the company will become classified as a "green stock" category of some kind, where the rate of return is not the sole evaluation criterion of the stockholders. These movements can be broadly interpreted: stakeholders (including stockholders) are cooperatively defining what value currency they consider to be relevant to guide their decisions. To emphasize, this value currency is cooperatively determined rather than exogenously imposed, and should be conducted in conjunction with the stakeholder engagement exercise in order for the principal-agent problem to apply.

To elaborate more on the various ramifications of creating a value currency will make our research agenda unmanageable as a paper. But the thought of this as an extension of the classical principal-agent problem in the conventional theory of firm literature is the insight we are putting forward here. If stakeholder involvement with firms extends to the joint acceptance of a value currency, stakeholder involvement with firms will less likely be perceived as inconsistent with shareholders' interests, as the latter sense of value will go beyond profit maximization.

The suggestion we are making here is unusual, but not so far-fetched that it has not been experimented within various places of the world. For example, there was an SOL in France, a Tesco or a LETS in UK, a Chiemgauer in Germany, and a Wir in Switzerland. In the USA, the Museum of Financial History in New York, in its display of currency used in different periods in the history of that country, there is a Berkshare currency note. Instead of the familiar phrase of "In God we Trust" printed on Federal Reserve Notes, Berkshare currency uses four key words, "Community, Economy, Ecology, Sustainability" as the defining characteristics of their currency. ${ }^{15}$ Our proposition is that, to the extent a value currency such as the Berkshare exists, stakeholder engagement exercises as a principal-agent problem can theoretically be formulated for an organization, in Berkshare units. The theory of stakeholders of firm, analyzed in Berkshare units, is expected to be identical to the theory of shareholders of firm, analyzed in Berkshare units. All of these, of course, further await a legal environment for institutionalizing the unique relationships in its stakeholder engagement process. We hope this will set the stage for future research in this direction.

\section{Conclusion}

Margolis and Walsh [8] articulated the motivation behind our study.

"The Challenge facing advocates of corporate social initiatives is to find a way to promote social justice in a world where the shareholder wealth maximization paradigm reigns supreme. Advocates for corporate social initiatives must be prepared to argue with a Nobel laureate in economics that such social initiatives do indeed benefit shareholders."

This paper utilizes the New Institutional Economics (NIE) paradigm to assess the valuation exercises for the stakeholder theory of firm. We argue that identifying the source of values for sustainability is important. Moreover, capturability of sustainable values must be executed via stakeholder engagement, incentive alignment, and a cooperative recognition of a value currency among the stakeholders. While these suggestions have yet to be seen to be widely practiced, our paper resorts to the recommendation of a Nobel-laureate worthy economist, Armen Alchian, who is seen by many in the academic field as someone representing a conservative school of thought in the advocacy of profit maximization. Yet, Alchian's 1950 article [3] emphatically denied profit maximization as a cause for action. It is important to know that results are to be distinguished from intents. In 1950, profit maximization might have been a winning criterion. Over the past six decades, academicians are fully aware of the many changes and paradigm shifts, affecting theoretical perspectives to be used as well as being affected by them. Now in the 21 st century, what counts as success could very well be different. Be it accounting, finance, or management practice, a firm's organizational structure and its role in an economy is evolutionary and evolving. It may take a long process of competition, across firms, across regions, and across countries, to sort out the best practice, if indeed there is one.

Let Alchian remind us: "What really counts is the various actions actually tried, for it is from these that "success" is selected, not from some set of perfect actions." (Page 220).

To this, deceased Nobel-laureate, George Stigler, would probably add: "The role of the user of a theory is a simple one: His is not to reason why, his is to sign and try." ${ }^{\prime 6}$ If one were to interpret the stakeholder theory of firms with the shareholder theory of firms in this broad paradigm, the implications of the two theories would likely converge.

\section{Acknowledgments}

The authors wish to thank Colin Laughan, Martha Welsh, and three anonymous referees for this paper.

\section{Endnotes}

1. The stakeholder concept of a firm is taught in management courses in many business schools, extending the scope of a firm's activities beyond those commonly recognized in economics and finance.

2. The definition of sustainable development is one adopted in Lai and Lorne $[9,10]$. Focusing on creating win-win possibilities between economy, environment, and society can be a more pragmatic criterion than that stipulated by Brundtland. This definition has been 
adopted in many sustainable development policies of the world; see Lorne [11].

3. According to Margolis and Walsh $[8,12]$, there was a "30-year history of empirical work on the search for a relationship between corporate social performance (CSP) and corporate financial performance (CFP)." Wagner and Schaltegger [13] remarked that "no unique relationship has prevailed in empirical studies so far." A comprehensive review of efforts for past work can be exhaustive and is not the purpose of this paper. Dillard et al. [14], page 80 and endnotes 4 and 5, however, provided useful information on many prior works. Page 88 of the article also informatively categorized research in this area into (a) efficacy of investing with environmental considerations, (b) extent and impacts of environmental disclosure, (c) relationship between corporate characteristics and environmental disclosures, (d) impacts of environmental accounting information on capital markets, (e) efficiency of accounting for environmental costs. In a working paper by the authors of this paper, we also made some attempts at this question by examining the effect of the announcement effect of firm values after they were included in the Dow Jones Sustainability World Index (DJSI World). With 116 firms used in our sample, our results were rather inconclusive.

4. The skepticism that financial performance can indeed capture sustainable values has been raised very early in the NIE literature; see Jensen [15].

5. NIE differs from traditional institutionalism in that the latter emphasizes only the legal foundation (the structure) of the institution and the economy, while the former includes additional economic factors such as agency costs, information costs, and various transaction costs in the analyses, Alchian and Demsetz [2], Williamson [16], Jensen and Meckling [17], Fama [18]Fama and Jensen [19], Ostrom [20], Sappington [21], Furubotn and Richter [22], and James [23]. A fairly comprehensive bibliography with annotation has been provided by Harvey James, Jr. of the University of Missouri at the website, http://web.missouri.edu/ jamesha/tce/index.htm.

6. Lai and Lorne $[9,10]$ interpreted sustainable development as endeavors to convert negative externalities into positive externalities. The conversion of liabilities into assets ought to be reflected in the balance sheet of firms for forging finance and accounting practices. We are aware that not all firms currently adopt this meaning of sustainable development, however.

7. In a session discussing stakeholder engagement on Designing Sustainability, organized by Portland State University in 2008, industry representatives uniformly and emphatically denounced green washing as the motivation for stakeholder engagement; that is, CSR were not done for publicity purpose only.

8. An Intel spokesman at the conference, while expressing open invitations to all NGOs to submit proposals to the company, hinted that the credibility of an NGO can greatly influence their decision as to which NGO they choose to work with. Again, this suggested a structure of information gathering being a crucial part of the stakeholder engagement process. The role of NGOs will be further discussed in the second example.

9. Schaltegger and Figge [24], Figge and Hahn [25], and Barkusky and Lorne [26].

10. Schaltegger and Figge [24], Figge and Hahn [25], and Barkusky and Lorne [26].

11. See http://www.unepfi.org/events/2008/london/index .html.

12. Based on documents received from the organizer of the working group, in email correspondence with the first author of this paper.

13. Frooman (1997), Epstein and Roy [27], and Emerson [28]. Brown et al. [29] had always advocated a more blended view of financial performance: "It is not a question of either/or, but rather, both/and. We need new metrics...".

14. "Only as the natural system components are commodified can they be incorporated into the neoclassical economic calculus" page 81, Dillard et al. [14]. In a 2009 paper taking a rather radical position, the common currency approach implicitly used in the triple bottom line methodology was further questioned as the appropriate method of evaluation for evaluating sustainability.

15. Berkshares notes are local currency that circulates in The Berkshires region of Massachusetts, USA. The region presumably practices a principle of sustainable development.

16. George Stigler, [30], p.6.

\section{References}

[1] R. H. Coase, "The nature of the firm," Economica, vol. 4, pp. 386-405, 1937.

[2] A. A. Alchian and H. Demsetz, "Production, information costs and economic organization," American Economic Review, vol. 62, no. 5, pp. 777-795, 1973.

[3] A. A. Alchian, "Uncertainty, evolution and economic theory," Journal of Political Economy, vol. 58, pp. 211-221, 1950.

[4] S. Schaltegger and R. L. Burritt, "Sustainability accounting for companies: catchphrase or decision support for business leaders?" Journal of World Business, vol. 45, no. 4, pp. 375-384, 2010.

[5] R. L. Burritt and S. Schaltegger, "Sustainability accounting and reporting: fad or trend?" Accounting, Auditing and Accountability Journal, vol. 23, no. 7, pp. 829-846, 2010.

[6] A. Kourula, "Evaluating cross-section partnerships-sponsorship, dialogue or strategic partnership?" in Proceedings of the 2nd Annual International Conference on Business and Sustainability: Designing Sustainability, Portland State University, October 2008.

[7] M. Halme and J. Laurila, "Philanthropy, integration or innovation? Exploring the financial and societal outcomes of 
different types of corporate responsibility," Journal of Business Ethics, vol. 84, no. 3, pp. 325-339, 2009.

[8] J. Margolis and J. P. Walsh, "Does Misery Love Companies? How Social Performance Pays Off," 2001, Harvard Business School Working Knowledge, http://hbswk.hbs.edu/item/2369 .html.

[9] L. W. C. Lai and F. T. Lorne, "Implementing sustainable development: institutional features," in Implementing and Understanding Sustainable Development, L. W. C. Lai and F. T. Lorne, Eds., chapter 1, Nova Science, New York, NY, USA, 2003.

[10] L. W. C. Lai and F. T. Lorne, "The coase theorem and planning for sustainable development," Town Planning Review, vol. 77, no. 1, pp. 41-73, 2006.

[11] F. Lorne, "Macro-entrepreneurship and sustainable development: the need for innovative solutions for promoting winwin interactions," Environmental Economics and Policy Studies, vol. 10, no. 2, 2009.

[12] J. D. Margolis and J. P. Walsh, "Misery loves companies: rethinking social initiatives by business," Administrative Science Quarterly, vol. 48, no. 2, pp. 268-305, 2003.

[13] M. Wagner and S. Schaltegger, "How does sustainability performance relate to business competitiveness?" Greener Management International, no. 44, pp. 5-16, 2003.

[14] J. Dillard, D. Brown, and R. S. Marshall, "An environmentally enlightened accounting," Accounting Forum, vol. 29, no. 1, pp. 77-101, 2005.

[15] M. C. Jensen, "Value maximization, stakeholder theory, and the corporate objective function," in Breaking the Code of Change, M. Beer and N. Nohria, Eds., HBS Press, 2000.

[16] O. E. Williamson, Markets and Hierachies: Analysis and Antitrust Implications, Free Press, New York, NY, USA, 1975.

[17] M. C. Jensen and W. H. Meckling, "Theory of the firm: managerial behavior, agency costs and ownership structure," Journal of Financial Economics, vol. 3, no. 4, pp. 305-360, 1976.

[18] F. Eugene, "Agency problems and the theory of the firm," Journal of Political Economy, vol. 88, no. 2, pp. 288-307, 1980.

[19] E. F. Fama and M. C. Jensen, "Organizational forms and investment decisions," Journal of Financial Economics, vol. 14, no. 1, pp. 101-119, 1985.

[20] E. Ostrom, Governing the Commons: The Evolution of Institutions for Collective Action, Cambridge University Press, New York, NY, USA, 1990.

[21] D. E. M. Sappington, "Incentives in principal-agent relationships," Journal of Economic Perspectives, vol. 5, no. 2, pp. 45-66, 1991.

[22] E. G. Furubotn and R. Richter, Institutions and Economic Theory: The Contribution of the New Institutional Economics, University of Michigan Press, Ann Arbor, Mich, USA, 1997.

[23] H. S. James Jr., New Ideas in Contracting and Organizational economics Research, Nova Science Publishers, Hauppauge, NY, USA, 2005.

[24] S. Schaltegger and F. Figge, "Environmental shareholder value: economic success with corporate environment management," Eco-Management and Auditing, vol. 7, no. 1, pp. 29-42, 2000.

[25] F. Figge and T. Hahn, "Value-oriented impact assessment: the economics of a new approach to impact assessment," Journal of Environmental Planning and Management, vol. 47, no. 6, pp. 921-941, 2004.

[26] M. Barkusky and F. Lorne, "Economic rationales for corporate social responsibility," International Journal of Environment, Workplace and Employment, vol. 2, no. 2-3, 2006.
[27] M. J. Epstein and M.-J. Roy, "Sustainability in action: identifying and measuring the key performance drivers," Long Range Planning, vol. 34, no. 5, pp. 585-604, 2001.

[28] J. Emerson, "The blended value proposition: integrating social and financial returns," California Management Review, vol. 45, no. 4, pp. 35-51, 2003.

[29] D. Brown, J. Dillard, and R. S. Marshall, "Strategically informed, environmentally conscious information requirements for accounting information systems," Journal of Information Systems, vol. 19, no. 2, pp. 79-103, 2005.

[30] G. J. Stigler, The Theory of Price, Macmillan, New York, NY, USA, 3rd edition, 1966, (in italics). 


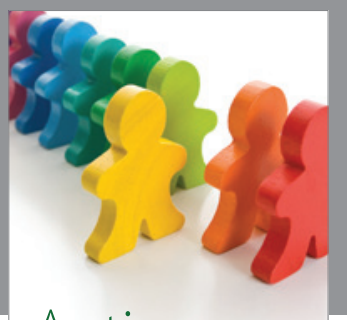

Autism

Research and Treatment
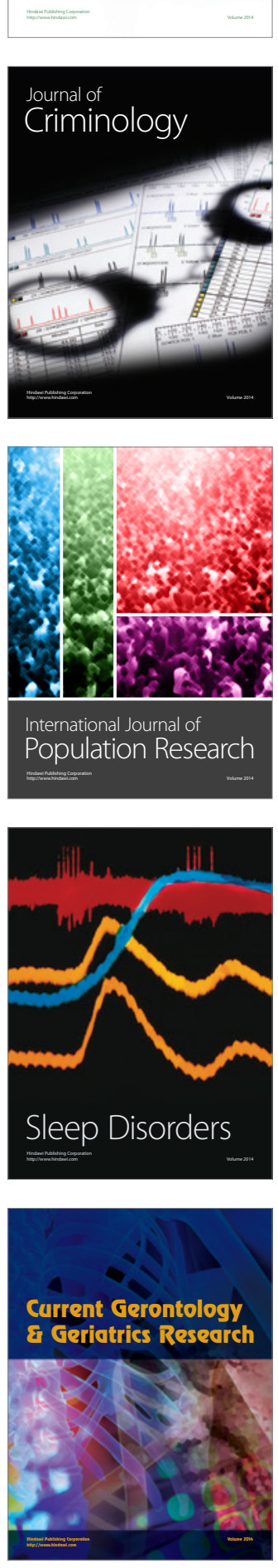
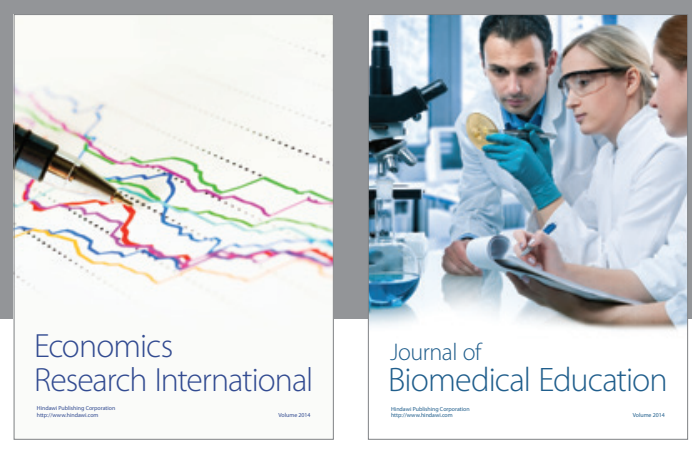

Journal of

Biomedical Education

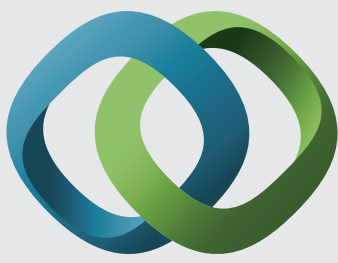

\section{Hindawi}

Submit your manuscripts at

http://www.hindawi.com
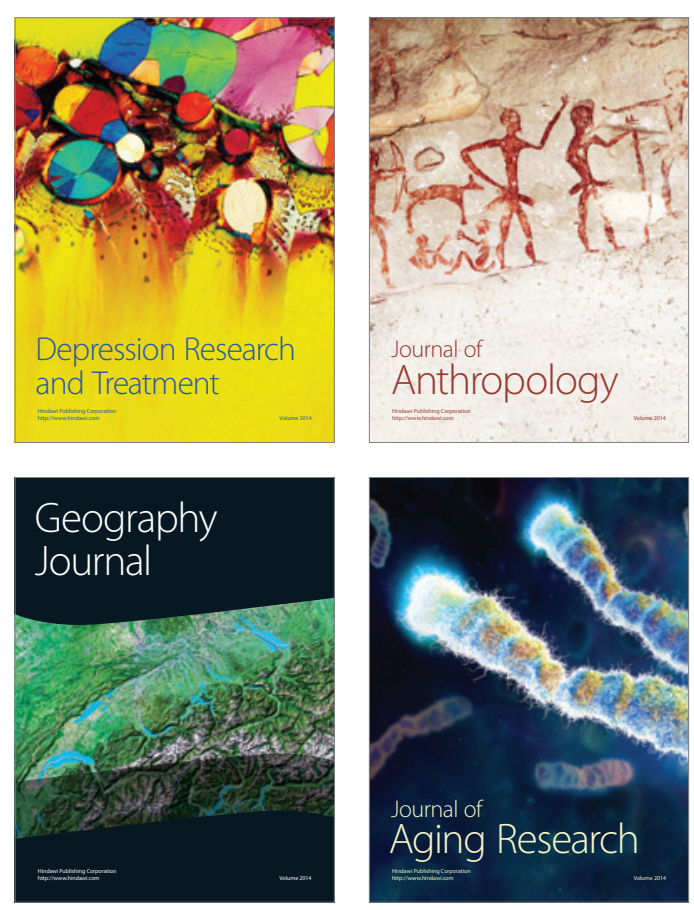

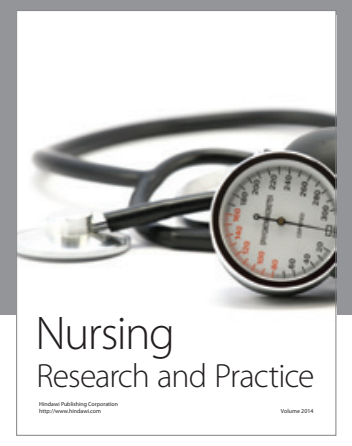

Nursing

Research and Practice

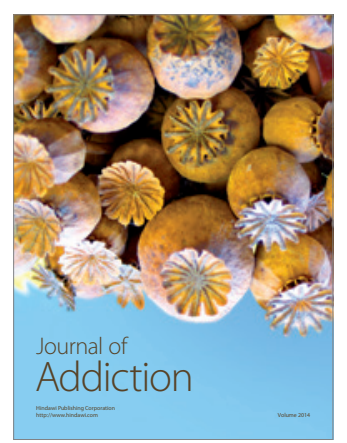

Child Development

Research

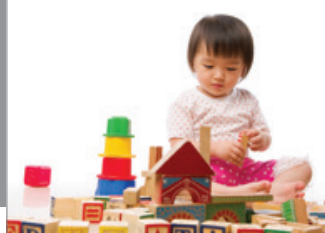

迥
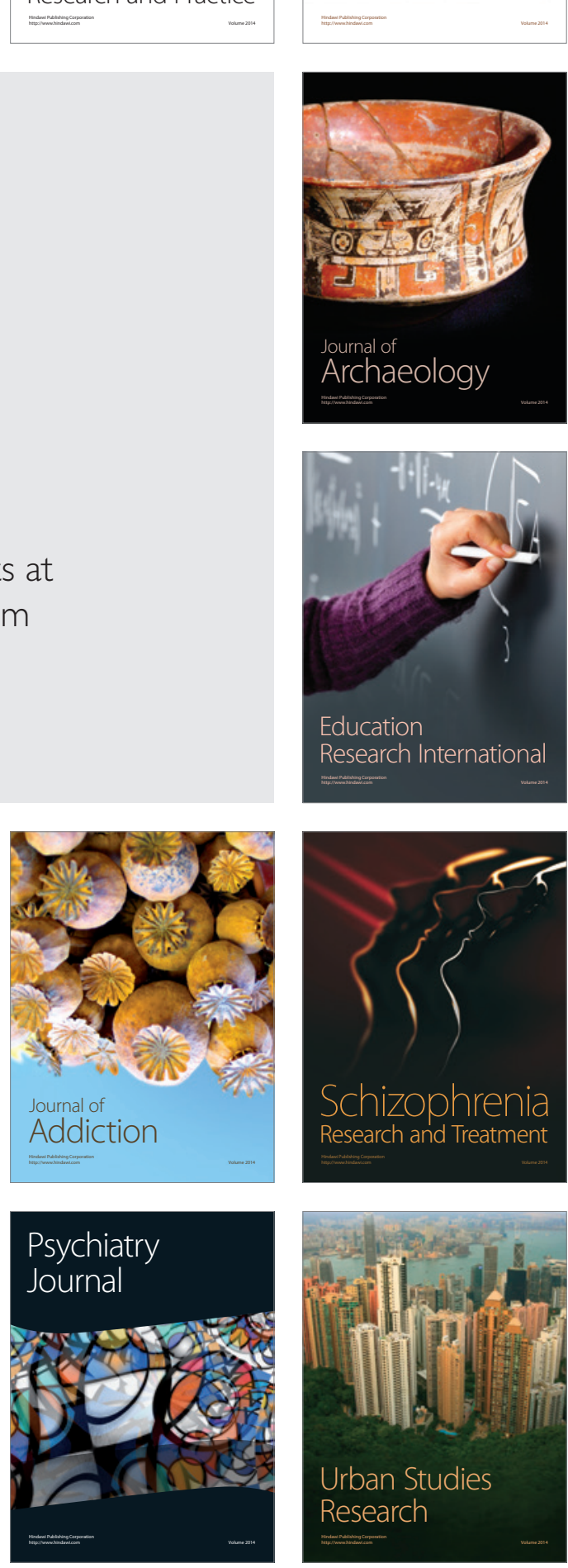